\title{
Integração de processos na cadeia de suprimentos e desempenho do serviço ao cliente: um estudo na indústria calçadista de Franca
}

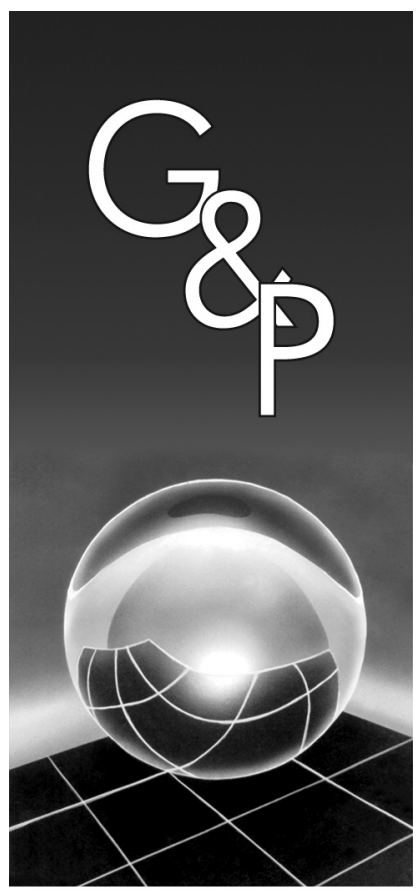

\author{
Wilson de Castro Hilsdorf \\ Roberto Gilioli Rotondaro \\ Silvio Roberto Ignacio Pires
}

Resumo

O processo de globalização e a revolução digital têm trazido novos desafios de competitividade às empresas. Uma dessas novas necessidades é a mudança do foco do escopo gerencial para toda a cadeia de suprimentos. Gerenciar uma cadeia de suprimentos requer, entre outros aspectos, a integração dos "processos-chave" de negócios ao longo dessa cadeia. Nesse sentido, este trabalho teve como objetivo identificar como é a relação entre a integração de processos ao longo da cadeia de suprimentos e o desempenho no serviço prestado ao cliente (customer service). Para tanto, a abordagem exploratória foi utilizada, tendo como objeto de estudo uma cadeia de suprimentos calçadista localizada na cidade de Franca, a qual se constitui em um bom exemplo de cadeia consolidada e já inserida no mercado internacional. Os resultados obtidos permitem concluir que o desempenho do serviço ao cliente na cadeia estudada está relacionado diretamente com a integração dos processos de atendimento de pedidos, gestão da demanda e desenvolvimento de produtos ao longo da cadeia, envolvendo não apenas a integração com clientes, mas também com os fornecedores-chave. Pode-se constatar ainda que esse desempenho está relacionado também com a existência de competências internas nos processos considerados, nas empresas estudadas.

Palavras-chave: Cadeia de suprimentos. Serviço ao cliente. Integração de processos. Indústria calçadista.

\section{Introdução}

A instabilidade dos mercados e a intensa competição entre as empresas vêm se tornando cada vez mais um grande desafio para a gestão empresarial. A partir da década de 90 o chamado processo de globalização expandiu significativamente a oferta de produtos em muitos setores industriais, sem que tenha havido um aumento proporcional no consumo. Com isto, as dimensões competitivas mais comuns como custo, qualidade e desempenho das entregas vêm dando lugar a uma nova tendência na qual o cliente exige cada vez mais produtos customizados com preços competitivos e aumento no nível de serviços. A flexibilidade para responder a essas novas exigências tornou-se um novo diferencial competitivo para as empresas. A lógica da customização em massa - mass customization - que visa compatibilizar as vantagens da produção em massa e da produção customizada é a nova perspectiva a ser atingida (SU, 2004). Os avanços na tecnologia da informação têm permitido às empresas atenuar o trade-off entre oferecer ao consumidor um produto com preço competitivo e ao mesmo tempo diferenciado ou customizado às suas necessidades, o que vem sendo obtido também pelo estabelecimento de parcerias e pela extrapolação do foco de gestão para toda a cadeia de suprimentos, com a utilização da tecnologia da informação para aumentar a eficiência dos processos de negócio ao longo da cadeia (HAYES et al., 2005).

Nesse contexto, a gestão da cadeia de suprimentos (Supply Chain Management - SCM) tem sido reconhecida gradativamente como a atividade de integração dos "processos-chave" de negócio por meio da cadeia de suprimentos (LAMBERT; COOPER, 2000; CROXTON; GARCÍA-DASTUGUE; LAMBERT, 2001; VICKERY et al., 2003).

Para vários autores, o aumento do nível de serviço ao cliente (customer service) decorre da efetiva gestão da cadeia de suprimentos e requer a integração total dos processos de negócio ao longo dessa cadeia, além da excelência operacional das empresas. Contudo, o estabelecimento da relação entre a integração de processos 
e o desempenho da cadeia de suprimentos no serviço ao cliente ainda carece de estudos mais aprofundados, no sentido de examinar de forma mais específica essa relação (CROXTON; GARCÍA-DASTUGUE; LAMBERT, 2001; VICKERY et al., 2003; TRKMAN et al., 2007; FROHLICH; WESTBROOK, 2001). Para Lee, Kwon e Severance (2007), faltam pesquisas para efetivamente medir o grau de integração dos processos e sua relação com medidas de desempenho em situações reais de cadeias de suprimentos.

Por sua vez, a indústria calçadista mundial tem se polarizado entre dois extremos. Segundo Costa (2002), de um lado tem-se a consolidação da China como grande exportador de calçados de baixo preço e com grande volume de produção. No outro extremo, tem-se o mercado representado pelo consumidor de maior poder aquisitivo, no qual a Itália aparece como a principal fonte fornecedora, devido principalmente à sua tradicional capacidade de criação e de design. No Brasil a indústria calçadista representa um setor importante da economia, sendo fortemente geradora de empregos e de divisas para o País, uma vez que ocupa o $11^{\circ}$ lugar no ranking das exportações segundo a Secretaria de Comércio Exterior do Ministério do Desenvolvimento Indústria e Comércio - SECEX/MDIC (2006). A indústria calçadista de Franca sempre foi muito representativa nesse setor, especialmente no que se refere à produção de calçados masculinos, sendo formada por cerca de 760 empresas e com capacidade instalada para produzir 37 milhões de pares por ano, conforme dados do Sindicato das Indústrias de Calçados de Franca - SINDIFRANCA (2006). Entretanto, com o crescimento da indústria calçadista chinesa, a indústria francana tem sido desafiada a buscar novas fontes de vantagens competitivas que não estejam mais ligadas apenas ao baixo custo produtivo. A opção mais natural é a busca pelo reposicionamento no mercado global com produtos mais diferenciados e de maior valor agregado, espelhado no caso italiano. Para tanto, a melhoria do desempenho do serviço ao cliente é peça fundamental.

Nesse contexto, este trabalho tem como objetivo principal identificar em que medida o desempenho no serviço ao cliente está associado à integração dos processos de negócios na cadeia de suprimentos em um conjunto de empresas fabricantes e exportadoras de calçados da cidade de Franca e alguns dos seus principais clientes importadores no exterior.

O artigo apresenta inicialmente uma revisão da literatura a respeito da abordagem de processos na cadeia de suprimentos e das medidas de desempenho no serviço ao cliente. $\mathrm{Na}$ sequência é apresentada a metodologia utilizada para a coleta de dados, seguindo-se a descrição e análise dos dados obtidos e as conclusões e considerações finais.

\section{Integração da cadeia de suprimentos}

Uma das principais e potencialmente mais produtivas tendências nas organizações tem sido a migração das estruturas funcionais para a estrutura por processos. Segundo
Davenport (1994), as atividades empresariais devem ser vistas não em termos de funções ou departamentos, mas sim em termos de "processos-chave". No âmbito interno de uma organização, a geração de um produto ou serviço para um cliente é realizada pela sequência concatenada de um ou mais processos interligados. Existe toda uma ligação entre clientes e fornecedores internos, mas o objetivo principal é a produção de um bem ou serviço para o cliente final. No âmbito da cadeia de suprimentos, a mesma relação cliente/fornecedor pode ser considerada, porém entre as diversas organizações que estão incluídas como membros da cadeia. Nestas interfaces, a integração dos processos torna-se particularmente difícil, uma vez que envolve a ligação entre organizações distintas, com diferentes culturas, diferentes estágios de desenvolvimento tecnológico e diferentes métodos de gestão, o que implica na necessidade de uma grande sinergia entre elas (LAMBERT; COOPER, 2000).

A implementação da gestão da cadeia de suprimentos requer que se faça a transição da estrutura funcional para a estrutura focada nos processos do negócio, inicialmente dentro de cada organização e, em seguida entre cada membro da cadeia (CROXTON; GARCÍA-DASTUGUE; LAMBERT, 2001).

O Global Supply Chain Forum, segundo Croxton, García-Dastugue e Lambert (2001), identificou 8 "processoschave" que compõem o ponto central da gestão da cadeia de suprimentos, quais sejam, gestão do relacionamento com clientes, gestão do serviço ao cliente, gestão da demanda, atendimento dos pedidos, gestão do fluxo de manufatura, gestão do relacionamento com fornecedores, desenvolvimento de produtos e comercialização e gestão de retornos.

Estes 8 "processos-chave" percorrem toda a extensão da cadeia e cruzam cada um de seus componentes e suas respectivas áreas funcionais. A integração de cada um destes processos dentro de cada organização que compõe a cadeia, assim como entre estas organizações, é tarefa primordial para a melhoria de seu desempenho e fornecimento de produtos e serviços de maior valor agregado aos clientes.

Aragão et al. (2004) também identificaram a integração dos processos de negócio como requisito crítico para o sucesso de uma cadeia de suprimentos, além da necessidade de identificação da sua estrutura, do compartilhamento de informações entre os seus membros-chave e da adoção de medidas de desempenho apropriadas que abranjam toda a cadeia.

O modelo apresentado por Lambert e Cooper (2000) torna-se particularmente importante. Esses autores definiram o nível de integração de uma cadeia de suprimentos em função do nível e do número de componentes adicionados a uma ligação, podendo variar de baixo a alto nível de integração. Ou seja, à medida que novos componentes de gestão vão sendo adicionados às ligações entre os membros de uma cadeia de suprimentos, maior tende a ser 
o nível de integração entre eles. Os autores propuseram nove componentes de gestão que podem ou devem ser observados para a gestão de uma cadeia de suprimentos, os quais foram divididos em dois grupos:

a) Grupo I: Componentes técnicos e físicos de gestão: planejamento e controle, estrutura de trabalho, estrutura de organização, estrutura para o fluxo de produtos e estrutura para o fluxo de informação.

b) Grupo II: Componentes gerenciais e comportamentais de gestão: métodos de gestão, estrutura de poder e liderança, estrutura de risco e recompensa e de cultura e atitude.

Mais uma tentativa de definir o nível de integração na cadeia de suprimentos foi feita por Frohlich e Westbrook (2001), que conduziram uma pesquisa na indústria metalmecânica, na qual o objetivo era o de comprovar a hipótese de que as empresas que apresentam um nível maior de integração com fornecedores e clientes teriam um melhor desempenho competitivo. $\mathrm{O}$ estudo foi baseado em oito atividades cujos fabricantes usualmente utilizam para integrar suas operações com fornecedores e clientes, as quais foram definidas a partir da literatura e da experiência dos pesquisadores no assunto. As atividades integrativas consideradas como base para a pesquisa foram: acesso ao sistema de planejamento; compartilhamento de planos de produção; utilização conjunta de EDI/Networks; conhecimento dos níveis e mix dos estoques; customização de embalagens; definição da frequência de entregas; uso comum de equipamentos logísticos/contêineres; e uso comum de operadores logísticos. As atividades integrativas consideradas por Frohlich e Westbrook (2001) são derivadas de decisões e acordos estratégicos entre as empresas parceiras, porém, por serem de caráter mais técnico e operacional, são mais facilmente mensuráveis.

\section{Medidas de desempenho no serviço ao cliente}

Muitos modelos de gestão da cadeia de suprimentos têm proposto sistemas de medição de desempenho que consideram a cadeia como um todo e colocam a implementação desse sistema de medição como fator crítico para o sucesso dessas cadeias (LAMBERT; POHLEN, 2001; STEPHENS, 2001; ARAVECHIA, 2001; ARAGÃO et al., 2004; BREWER; SPEH, 2000; KUEI, 2001). Hijjar, Gervásio e Figueiredo (2005) apresentam uma pesquisa publicada pelo CLM - Council of Logistic Management, segundo a qual as empresas com logística de classe mundial percebem a medição de desempenho da cadeia de suprimentos como uma competência crítica e têm desenvolvido medidas relacionadas a custos, serviço ao cliente e qualidade.

Considerando que os processos logísticos são caracterizados como processos cuja natureza é de um serviço que tem como objetivo principal o de prover utilidade de tempo e lugar para os produtos, fixaremos nossa atenção na medida do desempenho desses processos, denominada por muitos autores de serviço ao cliente. O conceito de serviço ao cliente é ainda frequentemente mal entendido ou simplificado. Do ponto de vista conceitual, existem algumas definições. Para Lambert, Stock e Ellram (1998), serviço ao cliente pode ser entendido como um processo que ocorre entre o comprador, o vendedor e uma terceira parte. $\mathrm{O}$ processo resulta em um valor agregado para o produto ou serviço oferecido, podendo estar, este valor, agregado em um processo de troca, presente em uma simples transação ou em contratos de longo relacionamento. Numa definição ampla, colocam o serviço ao cliente como uma medida de quão bem o sistema logístico está desempenhando seu papel de prover utilidade de tempo e lugar para os produtos e serviços. Assim, o serviço ao cliente seria a saída do sistema logístico e a interface entre as funções de marketing e logística. Na visão de processos, esses autores definem o serviço ao cliente como sendo: "Um processo para prover benefícios significativos de valor agregado à cadeia de suprimentos, de maneira eficiente em termos de custos". Lambert, Stock e Ellram (1998), apresentam uma série de medidas para avaliar o desempenho no serviço ao cliente, as quais podem ser resumidas basicamente pelo nível de disponibilidade do produto, pela velocidade e consistência no atendimento de pedidos e pela habilidade de se comunicar com os clientes e fornecer-lhes informações sobre os pedidos.

Figueiredo et al. (2002) elaboraram instrumento de pesquisa para medição do desempenho da indústria brasileira de alimentos na logística de distribuição, utilizando as seguintes dimensões do serviço ao cliente: disponibilidade de produto; tempo de ciclo do pedido; consistência do ciclo do pedido; frequência de entregas; flexibilidade do sistema de entregas; sistema de recuperação de falhas; sistema de suporte à informação; suporte à entrega; e suporte pós-entrega.

O modelo SCOR - Supply Chain Operations Reference Model versão 9.0 (2008) utiliza como atributos de desempenho do ponto de vista do cliente a confiabilidade, a velocidade de resposta e a agilidade, os quais no seu nível 1 são desdobrados em indicadores. Essas métricas são referências para o nível estratégico do modelo SCOR no seu nível 1 , não sendo necessariamente aplicáveis aos processos operacionais ao longo da cadeia de suprimentos, os quais estão incluídos nos níveis 2 e 3 do modelo.

Coyle, Bardi e Langley (2003) adotam uma definição que inclui o valor total na perspectiva do consumidor final. Assim, para estes autores:

serviço ao cliente é um processo para prover vantagem competitiva e agregar benefícios à cadeia de suprimentos, com o objetivo de maximizar o 
valor total ao consumidor final (COYLE; BARDI; LANGLEY, 2003).

Do ponto de vista da função logística, esses autores definem os quatro elementos para o serviço ao cliente como sendo, tempo, confiança, comunicações e conveniência e lembram que o novo ambiente de competição para as cadeias de suprimento resultou em padrões de desempenho muito mais rigorosos, sugerindo que a medida desse desempenho deve ser estabelecida sempre na perspectiva do cliente. Com isso, e de maneira coerente com a definição adotada e com o objetivo de maximizar o valor para o cliente, os quatro elementos do serviço ao cliente são desdobrados em medidas de desempenho.

A abordagem de Coyle, Bardi e Langley (2003) denota claramente uma mudança de paradigma no entendimento do significado do serviço ao cliente e, principalmente, na forma de avaliar o nível desse serviço (Tabela 1).

\section{Metodologia de pesquisa}

Dados os objetivos propostos para esta pesquisa e a abrangência do problema colocado, a abordagem utilizada foi do tipo exploratória, com vistas a proporcionar maior familiaridade com o problema e a constituir novas hipóteses que possam ser testadas em pesquisas subsequentes. A análise dos dados obtidos foi de natureza qualitativa. Segundo Lazzarini (1995), pesquisas exploratórias de cunho mais qualitativo, são mais aplicáveis em situações em que se deseja aprimorar ideias e aprofundar o entendimento sobre determinado problema.

$\mathrm{O}$ procedimento de pesquisa adotado para a coleta dos dados necessários foi o estudo de caso, uma vez que esse é o método mais adequado, segundo Yin (2001), quando o controle que o pesquisador tem sobre os eventos é muito reduzido. Além disso, o estudo de caso é também o mais recomendado para descrever e avaliar situações em que a questão de pesquisa é do tipo "como" e, o objetivo é o entendimento e a exploração em profundidade do fenômeno

Tabela 1. Elementos do serviço ao cliente $\times$ medidas de desempenho.

\begin{tabular}{ll}
\hline \multicolumn{1}{c}{ Elemento } & \multicolumn{1}{c}{ Medidas de desempenho } \\
\hline Tempo & Lead-time de entrega \\
Confiança & $\begin{array}{l}\text { Baixa variabilidade no lead-time de entrega. } \\
\text { Produto entregue sem danos ou perdas. } \\
\text { Correto atendimento do pedido. }\end{array}$ \\
& $\begin{array}{l}\text { Grau de utilização de meios eletrônicos } \\
\text { Comunicação recebimento de pedidos e separação de }\end{array}$ \\
& $\begin{array}{l}\text { produtos. } \\
\text { Grau de disponibilidade de informações sobre } \\
\text { o pedido. }\end{array}$ \\
& Flexibilidade no nível de serviço logístico. \\
\hline
\end{tabular}

Fonte: Coyle, Bardi e Langley (2003). estudado. Para Yin (2001), o estudo de caso não representa uma amostra, e o objetivo do pesquisador é expandir e generalizar teorias (generalização analítica) e não enumerar frequências (generalização estatística).

Segundo Ellram (2006), o método do estudo de caso vem se tornando mais bem aceito em pesquisas relacionadas à gestão de operações e à cadeia de suprimentos, como uma forma legítima e válida de adicionar subsídios a este campo de conhecimento que outros tipos de abordagem não conseguem suprir. Segundo a autora, os estudos de caso são úteis nas pesquisas relacionadas à cadeia de suprimentos, devido ao grau de implementação limitado do fenômeno de interesse.

Dois aspectos relevantes, mencionados pelos autores citados como necessários para garantir a validade das conclusões obtidas por meio desse método de pesquisa são a utilização de múltiplas fontes de evidências e a escolha de amostras focadas no objeto de estudo que possam ser observadas com transparência.

\section{Estudo de caso}

\subsection{Escopo e método}

A pesquisa de campo conduzida teve como objeto de estudo a cadeia calçadista da cidade de Franca em São Paulo, a qual se constitui em um exemplo consolidado e de resultados concretos já obtidos de uma cadeia de suprimentos setorial. O polo de Franca é o maior produtor de calçados masculinos do País, exportando seu produto desde o final da década de 60, atualmente para 58 países (Associação Brasileira da Indústria de Calçados - ABICALÇADOS, 2009). Na região de Franca encontram-se empresas representantes de todas as etapas do processo produtivo, desde os fornecedores das matérias-primas utilizadas até os representantes do consumidor final, além do que, pela sua característica fortemente exportadora a cadeia está inserida na "nova economia" (HAYES et al., 2005), estando sujeita às mais atuais tendências e exigências do mercado internacional, não só em relação à qualidade do produto como também em relação ao nível de serviço prestado aos clientes, os quais são representados na região por escritórios de agenciamento de exportações.

A Figura 1 ilustra e delimita a cadeia de suprimentos genérica que fora objeto de estudo neste trabalho, a qual será doravante chamada simplesmente de "Cadeia Calçadista de Franca" (CCF).

O método utilizado para a coleta dos dados está descrito a seguir:

a) Coleta de depoimento do diretor executivo do SINDIFRANCA - Sindicato da Indústria de Calçados de Franca, com o objetivo de identificar a estrutura da cadeia, seus membros-chave, principais processos de negócio, nível de integração dos processos, 


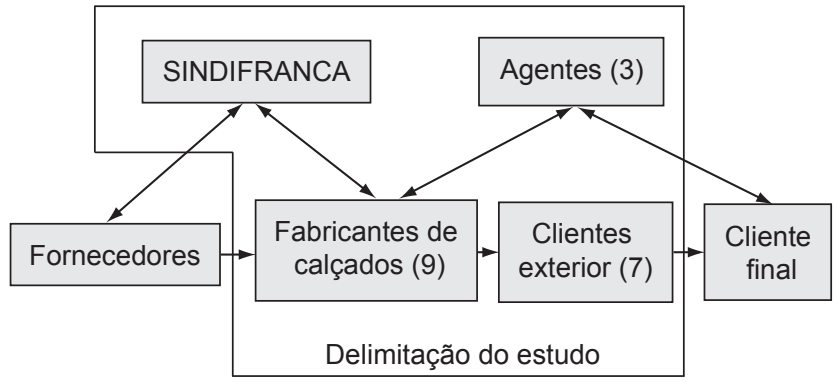

Figura 1. Cadeia calçadista de Franca. Fonte: autor.

práticas utilizadas, fluxos de informação e materiais, conjuntura econômica atual, presença da cadeia no mercado internacional, além de outros dados que pudessem ser relevantes para o objetivo da pesquisa. Esses dados foram complementados com outros dados obtidos de fontes secundárias, tais como, artigos técnicos, publicações do setor e sites.

b) Entrevistas com proprietários, diretores ou gerentes de nove entre as dez maiores empresas fabricantes e exportadoras de calçados da região, responsáveis por $61 \%$ do total exportado segundo o SINDIFRANCA (2006), com o objetivo de medir o grau de integração dos processos logísticos com seus clientes importadores. Estas entrevistas foram conduzidas com o auxílio de questionário semiestruturado utilizando escala de Likert de 1 (discordo inteiramente) a 5 (concordo plenamente) para cada uma das afirmativas propostas acerca da efetiva prática dos fatores de integração considerados. A utilização da escala de Likert teve como objetivo facilitar a obtenção das respostas e a interpretação das informações obtidas. Yin e Heald (1975), apud Lazzarini (1995), propõem a utilização de questionários com questões fechadas, aplicadas a um analista selecionado para cada caso específico, com o objetivo de elevar a confiabilidade da pesquisa, além de potencializar o processo de coleta de dados. A versão inicial do questionário foi testada em duas entrevistas piloto em empresas fabricantes, tendo sofrido alterações no número de questões e na terminologia para adequação àquela utilizada no setor. Também se verificou que alguns aspectos relacionados às atividades integrativas merecem o registro dos comentários dos entrevistados, em função das especificidades que tais atividades podem ter para uma determinada empresa ou para a própria cadeia. Ao final da entrevista foram também efetuadas verificações in loco em boa parte das empresas visitadas acerca das informações obtidas.

c) Entrevistas com os três maiores agentes de exportação estabelecidos na região, com o objetivo de avaliar o desempenho das empresas exportadoras no serviço aos clientes, na visão desses agentes. Essas entrevistas foram conduzidas com o auxílio de questionário semiestruturado também utilizando escala de Likert com o índice 1 da escala correspondendo ao "muito insatisfeito" e o índice 5 ao "muito satisfeito" com o desempenho dos fabricantes no indicador sugerido. A versão inicial do questionário foi submetida a dois agentes exportadores com o objetivo de testar e validar seu conteúdo. Logo de início ficou evidente a importância da atividade de desenvolvimento de novos produtos como elemento do serviço ao cliente já que é prática usual na cadeia a necessidade de fornecimento de amostras de cada novo modelo de calçado para a aprovação, antes da assinatura dos contratos. Este elemento foi então acrescentado ao questionário. Foram também verificados relatórios de divergências emitidos pelos clientes importadores e históricos de indicadores de desempenho elaborados pelos agentes, com o objetivo de subsidiar as respostas obtidas nas entrevistas.

d) Levantamento junto a sete clientes importadores de calçados para avaliar a satisfação com o desempenho das empresas fabricantes no serviço aos clientes. Estes clientes foram contatados por correio eletrônico, por intermédio dos agentes locais em Franca. Foi enviado a eles o mesmo questionário utilizado na etapa anterior, na sua versão em inglês.

\subsection{Objetivos e variáveis de pesquisa}

O objetivo principal deste trabalho foi o de identificar em que medida o desempenho da CCF no serviço ao cliente está associado à integração dos processos entre os fabricantes de calçados e seus clientes no mercado internacional.

Para a obtenção de dados que permitissem o alcance deste objetivo principal foram definidos os seguintes objetivos intermediários:

1) Determinar os fatores de integração dos processos logísticos e os elementos do serviço ao cliente na cadeia de suprimentos.

2) Propor matriz de relacionamento entre os fatores de integração dos processos e os elementos do serviço ao cliente.

3) Estabelecer critérios para medição do grau de integração dos processos na CCF e do seu desempenho no serviço ao cliente.

4) Aplicar os critérios estabelecidos para prospectar informações estruturadas e detalhadas da cadeia.

5) Analisar os dados obtidos e identificar evidências de relacionamento entre o desempenho no serviço ao cliente e o grau de integração dos processos, na CCF.

A definição das variáveis de pesquisa partiu da identificação na literatura relevante sobre o assunto, dos fatores que definem a integração de processos, dos elementos 
do serviço ao cliente na cadeia de suprimentos a serem utilizados como referência e dos respectivos indicadores de desempenho. Considerando que o conceito de serviço ao cliente, conforme definido no item 3 , é relacionado diretamente às atividades do sistema logístico na cadeia de suprimentos, foram utilizados como arcabouço teórico para delimitação das variáveis a serem utilizadas para a pesquisa os processos-chave denominados "gestão da demanda" e "atendimento de pedidos" pelo Global Supply Chain Forum em Croxton, García-Dastugue e Lambert (2001), os quais envolvem basicamente subprocessos de natureza logística, tais como, processamento de pedidos, gestão de estoques, embalagem e manuseio de produtos, transporte e entrega e gestão da informação sobre o pedido (BOWERSOX; CLOSS, 2001; BALLOU, 1999). Com isso, o modelo de integração de Frohlich e Westbrook (2001) e as atividades integrativas por eles propostas tornaram-se mais apropriadas como referência, não só por estarem focadas nos processos de natureza logística, como também por serem de caráter mais técnico e operacional, sendo mais facilmente mensuráveis. A partir destas atividades, foram definidos os 8 fatores de integração a serem utilizados como referência para construção do instrumento de pesquisa, conforme segue:

F1: definição da frequência de entregas;

F2: customização de embalagens;

F3: compartilhamento dos planos de produção;

F4: uso comum de equipamentos logísticos/contêineres;

F5: conhecimento dos níveis e mix dos estoques;

F6: acesso ao sistema de planejamento;

F7: uso comum de operadores logísticos; e

F8: utilização conjunta de EDI/Networks.

Para determinação dos elementos do serviço ao cliente, utilizados como referência, partiu-se do contexto da competitividade na chamada "nova economia", segundo a qual o desempenho deve ser medido em termos do valor agregado ao cliente pela cadeia de suprimentos (HAYES et al., 2005). Deste modo, as definições para serviço ao cliente que incluem o objetivo de maximizar o valor ao cliente final da cadeia nos pareceram mais bem enquadradas nessa nova tendência. Por este motivo, os elementos do serviço ao cliente e as respectivas medidas de desempenho adotadas por Coyle, Bardi e Langley (2003) descritas no item 3 foram utilizados para definição dos indicadores a serem considerados para a construção do instrumento de pesquisa (Tabela 2).

\subsection{Proposição de pesquisa}

Uma vez definidas as variáveis de pesquisa, foi proposta a matriz a seguir, que estabelece por meio dos elementos do serviço ao cliente o relacionamento a ser testado entre as 2 variáveis, os fatores de integração de processos $(F)$ e os indicadores de desempenho (I) na CCF (Tabela 3).

Segundo Gil (2002), hipóteses podem ser elaboradas para estabelecer a relação de associação entre variáveis, com o objetivo de indicar a força ou o sentido desta relação sem, no entanto, estabelecer relação de causalidade ou dependência. Yin (2001), considerando que o objetivo básico do estudo de caso é explorar e clarificar o fenômeno em estudo, prefere não falar em hipóteses, mas sim em proposições de pesquisa. Daí, a partir da matriz de relacionamento entre os fatores de integração e os indicadores de desempenho, foi feita a seguinte proposição: o desempenho da CCF no serviço ao cliente está associado à implementação dos fatores de integração dos processos de gestão da demanda e atendimento de pedidos entre os fabricantes e seus clientes.

\section{Apresentação e discussão dos dados}

\subsection{Fatores de integração da cadeia}

Foram visitadas nove entre as 10 maiores empresas fabricantes e exportadoras de calçados de Franca, responsáveis por $61 \%$ do total exportado. Os resultados obtidos estão descritos a seguir. Os índices apresentados referem-se à escala de Likert mencionada no item 5.1b):

\section{a) Fator F1: definição da frequência de entregas}

Afirmativa apresentada aos entrevistados: A frequência de entrega dos pedidos para exportação é definida de forma antecipada, clara e consistente junto aos principais clientes.

Constatações: Todos os entrevistados responderam concordar plenamente com a afirmativa apresentada (índice 5). Em todas as entrevistas realizadas ficou claro que as frequências de entrega dos pedidos são muito bem definidas entre fabricantes e clientes, sendo negociadas em cada caso específico e formalmente registradas em contrato.

Tabela 2. Matriz de relacionamento. Elementos do serviço ao cliente $\times$ indicadores de desempenho.

\begin{tabular}{|c|c|c|c|c|}
\hline & \multicolumn{4}{|c|}{ Elementos do serviço ao cliente } \\
\hline Indicadores & Tempo & Confiança & Comunicação & Conveniência \\
\hline I1 & & X & & \\
\hline I2 & $\mathrm{X}$ & & & \\
\hline I3 & & $\mathrm{X}$ & & \\
\hline I4 & & $X$ & & \\
\hline I5 & & & $\mathrm{X}$ & \\
\hline I6 & & & & $\mathrm{X}$ \\
\hline I7 & & & & $X$ \\
\hline
\end{tabular}

I1: \% de pedidos recebidos no prazo, completos e corretos; I2: lead-time de entrega; I3: índice de ocorrência de erros na cobrança; I4: índice de ocorrência de perdas e danos do produto; I5: facilidade de comunicação com a empresa e disponibilidade de informações sobre o pedido; I6: habilidade no desenvolvimento de novosprodutos; $\mathrm{eI}$ : facilidadedeatendimentoarequisitosespeciais (prazos, quantidades, tipos, embalagens, locais de entrega, etc.). Fonte: autor. 
Tabela 3. Matriz de relacionamento. Fatores de integração $\times$ indicadores de desempenho.

\begin{tabular}{|c|c|c|}
\hline Fatores de integração & $\begin{array}{c}\text { Elemento do } \\
\text { serviço ao cliente }\end{array}$ & Indicadores de desempenho \\
\hline $\begin{array}{l}\text { Definição de frequência de entregas (F1) } \\
\text { Compartilhamento de planos de produção (F3) } \\
\text { Acesso ao sistema de planejamento (F6) }\end{array}$ & Tempo & "Lead-time" de entrega (I2) \\
\hline $\begin{array}{l}\text { Compartilhamento de planos de produção (F3) } \\
\text { Uso comum de equipamentos logísticos (F4) } \\
\text { Conhecimento dos níveis e mix dos estoques (F5) } \\
\text { Acesso ao sistema de planejamento (F6) } \\
\text { Uso comum de operadores logísticos (F7) }\end{array}$ & Confiança & $\begin{array}{l}\text { \% de pedidos recebidos no prazo, completos e corretos (I1) } \\
\text { Índice de ocorrência de erros na cobrança (I3) } \\
\text { Índice de ocorrência de perdas e danos do produto (I4) }\end{array}$ \\
\hline Utilização conjunta de EDI/Networks (F8) & Comunicação & $\begin{array}{l}\text { Facilidade de comunicação com a empresa e } \\
\text { disponibilidade de informações sobre o pedido (I5) }\end{array}$ \\
\hline $\begin{array}{l}\text { Customização de embalagens (F2) } \\
\text { Compartilhamento de planos de produção (F3) }\end{array}$ & Conveniência & $\begin{array}{l}\text { Facilidade de atendimento a requisitos especiais (prazos, } \\
\text { quantidades, tipos, embalagens, locais de entrega, etc. (I7) } \\
\text { Habilidade no desenvolvimento de novos produtos (I6) }\end{array}$ \\
\hline
\end{tabular}

Fonte: autor.

\section{b) Fator F2: customização de embalagens}

Afirmativa apresentada aos entrevistados: As embalagens para transporte e entrega dos produtos para exportação são projetadas e executadas exatamente de acordo com as necessidades e exigências dos clientes.

Constatações: Dos 9 entrevistados, 6 responderam concordar plenamente com a afirmativa apresentada (índice 5) sendo que 3 responderam apenas concordar (índice 4).

Na maioria absoluta dos contratos para exportação o grau de exigência com relação às embalagens é extremamente elevado. As especificações são formalizadas em fichas técnicas na quais constam todos os detalhes quanto à embalagem e identificação dos produtos. Pode-se constatar in loco que os fabricantes francanos estão preparados e atendem plenamente a todas as exigências nesse sentido, o que reflete em índices desprezíveis de danos ao produto e reclamações por parte dos clientes. Pode-se concluir que existe um alto grau de implementação deste fator de integração entre fabricantes e clientes.

\section{c) Fator F3: compartilhamento dos planos de produção}

Afirmativa apresentada aos entrevistados: O planejamento dos programas de produção para exportação é feito de forma compartilhada com os clientes, baseado nas previsões da demanda destes.

Constatações: 7 entrevistados responderam nem concordar nem discordar da afirmativa (índice 3 ) e somente 2 responderam concordar com ela (índice 4).

O que se pode constatar é que não há nenhum mecanismo formal e sistemático para compartilhamento dos planos de produção entre clientes e fabricantes. Como o calçado é um produto com grande variedade de modelos que são continuamente substituídos, não há como obter com muita antecedência e em detalhes as características da demanda. Em geral, os planos de produção são elaborados pelas áreas competentes de cada fabricante, levando em conta os prazos negociados em cada contrato. Pode-se concluir que existe um grau médio de implementação deste fator de integração entre fabricantes e clientes.

\section{d) Fator F4: uso comum de equipamentos logísticos/contêineres}

Afirmativa apresentada aos entrevistados: Os equipamentos e recipientes para movimentação e transporte dos produtos para exportação, tais como veículos, paletes e contêineres, são padronizados de acordo com a necessidade dos clientes.

Constatações: Dos 9 entrevistados, 5 responderam concordar plenamente com a afirmativa (índice 5) e 4 responderam somente concordar com ela (índice 4).

Dadas as características do produto e os altos volumes contratados, o transporte é feito via marítima em contêineres. Nas entregas para o mercado norte-americano, os produtos são paletizados na chamada "embalagem coletiva" que são rigorosamente especificadas pelos clientes. Os fabricantes são responsáveis pela entrega do produto na condição FOB (free on board) no porto de embarque, ficando a conteinerização e o embarque por conta de empresa especializada contratada pelo cliente. Pode-se concluir que existe um alto grau de implementação deste fator de integração entre fabricantes e clientes, considerando-se as características da operação e os limites de responsabilidade dos fabricantes.

\section{e) Fator F5: conhecimento dos níveis e mix dos estoques}

Afirmativa apresentada aos entrevistados: A empresa tem pleno conhecimento dos níveis e mix dos estoques de produtos dos clientes importadores de forma a gerenciar sua reposição.

Constatações: Todos os entrevistados responderam discordar inteiramente da afirmativa, por se tratar de uma prática não aplicável à CCF. Na verdade, como se trata de 
um produto sujeito às tendências da moda, a cada estação são desenvolvidos novos modelos que substituem os anteriores, não sendo mantidos estoques pelos clientes, nem havendo a prática de reposição de quantidades além daquela negociada em cada contrato. Consideramos, portanto, o fator de integração F5, como não aplicável à CCF.

\section{f) Fator F6: acesso ao sistema de planejamento}

Afirmativa apresentada aos entrevistados: A empresa tem pleno acesso ao sistema de planejamento da demanda e previsão de vendas dos clientes importadores, de forma a planejar a programação da produção.

Constatações: Todos os entrevistados responderam discordar inteiramente da afirmativa, por não se tratar de uma prática aplicável à CCF. Por este motivo, consideramos o fator de integração F6 como também não aplicável à CCF.

\section{g) Fator F7: uso comum de operadores logísticos}

Afirmativa apresentada aos entrevistados: A seleção e contratação dos operadores logísticos para transporte e entrega dos produtos de exportação é feita de comum acordo com os clientes.

Constatações: Dos 9 entrevistados, 8 responderam nem concordar nem discordar da afirmativa (índice 3) e 1 respondeu discordar dela (índice 2). O que se pode constatar é que a responsabilidade pelas operações logísticas desde a saída do produto da fábrica até o destino final no cliente é estabelecida em contrato e compartilhada entre o fabricante e o cliente. Ao fabricante cabe entregar o produto na condição FOB (free on board) no porto de embarque, utilizando transportadora própria ou por ele escolhida e contratada. Pode-se concluir que existe um grau médio de implementação deste fator de integração entre fabricantes e clientes.

\section{h) Fator F8: utilização conjunta de EDI/Networks}

Afirmativa apresentada aos entrevistados: O processo de comunicação com os clientes importadores é totalmente informatizado, sendo a transmissão de dados e informações sobre os pedidos feitas por meio eletrônico.

Constatações: Dos 9 entrevistados 3 responderam concordar plenamente com a afirmativa (índice 5), 3 responderam concordar com ela (índice 4) e outros 3 nem concordar nem discordar (índice 3). Esse resultado demonstra diferentes graus de implementação de sistemas informatizados de comunicação, o que está relacionado à maior ou menor dependência de cada fabricante dos agentes intermediários. Como o processo de comercialização dos produtos no mercado externo é dominado por eles, todo o processo de comunicação com os clientes passa pela sua intermediação, desde a colocação dos pedidos até as informações sobre seu processamento. Na maioria dos fabricantes pode ser observada a existência de sistemas informatizados de gestão do tipo ERP - Enterprise Resource Planning, o que possibilita a manutenção de controle da produção de forma mais acurada e a disponibilização de informações mais precisas sobre o processamento dos pedidos. Pode-se concluir que existe um alto grau de implementação deste fator de integração entre fabricantes e clientes, considerando-se a presença dos agentes intermediários como facilitadores.

O resultado obtido é sintetizado na Tabela 4.

\subsection{Indicadores de desempenho}

Conforme descrito no item 5.1, foram contatados os 3 maiores agentes de exportação estabelecidos na região de Franca, além de 7 clientes norte-americanos grandes importadores de calçados da CCF. Utilizando como base os dados do SINDIFRANCA sobre a exportação de calçados no ano de 2005 e o volume de negócios no mesmo ano informado por cada um dos clientes, concluímos que estes foram responsáveis por cerca de $60 \%$ do volume importado pelo mercado norte-americano no ano de 2005. Os resultados obtidos levaram às seguintes constatações:

Nos indicadores I1 - \% de pedidos recebidos no prazo, completos e corretos, I3 - índice de ocorrência de erros na

Tabela 4. Resultados da pesquisa de campo - fatores de integração.

\begin{tabular}{|c|c|c|c|c|c|c|c|c|c|}
\hline \multirow[t]{2}{*}{ Empresa } & \multirow[t]{2}{*}{ Entrevistado } & \multicolumn{8}{|c|}{ Fatores de integração } \\
\hline & & F1 & F2 & F3 & F4 & F5 & F6 & F7 & F8 \\
\hline A & Dir. Exportação & 5 & 5 & 4 & 4 & NA & NA & 3 & 3 \\
\hline B & Proprietário & 5 & 5 & 3 & 5 & NA & NA & 3 & 3 \\
\hline $\mathrm{C}$ & Dir. Exportação & 5 & 4 & 3 & 4 & NA & NA & 2 & 4 \\
\hline $\mathrm{D}$ & Proprietário & 5 & 5 & 4 & 5 & NA & NA & 3 & 5 \\
\hline $\mathrm{E}$ & Ger. Exportação & 5 & 4 & 3 & 5 & NA & NA & 3 & 5 \\
\hline $\mathrm{F}$ & Ger. Exportação & 5 & 5 & 3 & 4 & NA & NA & 3 & 5 \\
\hline G & Ger. Exportação & 5 & 5 & 3 & 4 & NA & NA & 3 & 4 \\
\hline $\mathrm{H}$ & Proprietário & 5 & 5 & 3 & 5 & NA & NA & 3 & 3 \\
\hline I & Proprietário & 5 & 4 & 3 & 5 & NA & NA & 3 & 4 \\
\hline & Média & 5,0 & 4,7 & 3,2 & 4,6 & NA & NA & 2,9 & 4,0 \\
\hline
\end{tabular}

Fonte: autor. 
cobrança e I4 - índice de ocorrência de perdas e danos ao produto, os clientes contatados expressam satisfação com o desempenho da cadeia, não havendo discrepâncias relevantes nas respostas. É importante ressaltar também que a percepção dos clientes com relação a esses indicadores é a mesma dos agentes locais entrevistados. As informações complementares obtidas indicam que esse nível de satisfação é decorrência do processo de negociação bem executado e de uma certa maturidade no relacionamento entre fabricantes, agentes e clientes importadores, o que faz com que as rotinas para negociação, cobrança, transporte e entrega dos produtos estejam bem estabelecidas e implementadas.

$\mathrm{O}$ indicador $\mathrm{I} 2$ - lead-time de entrega mostra forte tendência dos clientes para a insatisfação com o desempenho da cadeia, apesar de haver alguma discrepância nas respostas. Essa discrepância pode ser explicada, provavelmente, pelo desempenho isolado de um ou outro fabricante com o qual o cliente concentrou seus negócios no período considerado e pela ação intermediadora dos agentes em casos específicos. A cadeia sofre forte pressão para redução dos prazos de entrega dos pedidos devido aos novos parâmetros colocados pelos competidores asiáticos no mercado, que são capazes, segundo os entrevistados, de atender a grandes pedidos, enviar orçamentos e amostras com muito maior rapidez do que os fabricantes francanos.

Nos indicadores I5 - facilidade de comunicação com a empresa e disponibilidade de informações sobre o pedido, e I6 - habilidade no desenvolvimento de novos produtos, os resultados mostram a tendência dos clientes para a satisfação com o desempenho da cadeia, não havendo discrepâncias nas respostas. Esse resultado mostra que a percepção do cliente importador nesses atributos é diferente daquela dos agentes intermediários locais, o que pode ser explicado pelo fato de haver, entre os fabricantes, diferentes estágios de implementação de sistemas eletrônicos de comunicação e gestão de informações e de estruturas de criação e design para o desenvolvimento de novos produtos, sendo as deficiências ainda existentes supridas por estruturas criadas pelos próprios agentes locais, o que faz com que o cliente importador não as perceba.

No indicador I7 - facilidade de atendimento a requisitos especiais, a tendência observada é de neutralidade em relação ao desempenho da cadeia, com respostas discrepantes entre a satisfação e a insatisfação. Esse resultado é coerente com o obtido junto aos agentes e pode ser explicado pela amplitude de aspectos que podem ser levados em conta na avaliação e pelos diferentes estágios de evolução dos fabricantes de calçados de Franca na flexibilização de seus processos. Para facilitar a interpretação dos entrevistados quanto ao significado deste indicador, foi solicitado que se considerasse a flexibilidade dos fabricantes para atender a requisitos diferentes dos usualmente solicitados com relação a prazos, quantidades, modelos, embalagens, locais de entrega, além de outras condições de fornecimento. Em alguns fabricantes, é possível verificar de fato evidências de flexibilidade no planejamento de produção para possibilitar remanejamentos nos programas e atender a emergências, bem como de flexibilidade nos processos de produção que permitem que possam ser fabricados pequenos lotes, além da possibilidade de atendimento de requisitos especiais de embalagem.

O resultado obtido é apresentado na Tabela 5.

\subsection{Análise e discussão}

Para denominação dos processos foi utilizada a nomenclatura do Global Supply Chain Forum (CROXTON; GARCÍA-DASTUGUE; LAMBERT, 2001), apresentada no item 2. No processo de "atendimento de pedidos" estão incluídas as atividades, ou subprocessos de processamento, embalagem, expedição, transporte e entrega do produto e manutenção e gestão de informações sobre o pedido (BOWERSOX; CLOSS, 2001; BALLOU, 1999).

Verificou-se que, com relação ao elemento "tempo" do serviço ao cliente, a implementação do fator de integração, que consiste na definição clara e formal das frequências de entrega dos pedidos estabelecidas a partir da negociação das condições contratuais entre os fabricantes de calçados e seus clientes e o mero cumprimento desses prazos, não implica na satisfação dos clientes. As evidências obtidas no caso estudado permitiram confirmar a afirmativa que, no contexto da nova economia, a agilidade e a capacidade de oferecer prazos de entrega cada vez mais curtos tornaram-se condições valorizadas pelo cliente. $\mathrm{Na} \mathrm{CCF}$, cuja demanda é fortemente influenciada por fatores sazonais ligados às tendências da moda, os novos parâmetros colocados no mercado pelos concorrentes asiáticos têm feito aflorar as dificuldades existentes para melhoria do desempenho da cadeia na redução de prazos e agilidade nas entregas, devido à falta de integração entre fabricantes e seus principais fornecedores. Os fatos constatados permitem afirmar que o desempenho da cadeia no elemento "tempo" do serviço ao cliente, além da integração com os clientes a jusante da empresa focal da cadeia no processo de atendimento de pedidos no que se refere ao seu processamento, está relacionado também à integração com os fornecedores a montante, no caso dos materiais e insumos principais necessários à produção. Pode-se afirmar também que a

Tabela 5. Desempenho no customer service na visão dos clientes.

\begin{tabular}{lllllllll}
\hline Empresa & País & \multicolumn{7}{c}{ Indicador } \\
\cline { 3 - 9 } (nome ou "sede") & & I1 & I2 & I3 & I4 & I5 & I6 & I7 \\
\hline Cole Haan & EUA & 3 & 1 & 4 & 4 & 4 & 3 & 3 \\
Harbor & EUA & 4 & 4 & 4 & 4 & 4 & 4 & 4 \\
"Califórnia" & EUA & 4 & 2 & 4 & 4 & 3 & 3 & 2 \\
"New York" & EUA & 4 & 1 & 4 & 4 & 4 & 3 & 3 \\
Old Dominion & EUA & 4 & 4 & 4 & 4 & 4 & 4 & 4 \\
"Missouri" & EUA & 4 & 2 & 4 & 4 & 4 & 4 & 2 \\
"Tennesse" & EUA & 4 & 2 & 4 & 4 & 4 & 4 & 3 \\
& Média & 3,9 & 2,3 & 4,0 & 4,0 & 3,9 & 3,6 & 3,0 \\
\hline
\end{tabular}

Fonte: autor. 
integração do processo de gestão da demanda que permitisse o compartilhamento das informações sobre suas características, desde os clientes importadores até os fornecedores dos insumos principais, poderia levar à antecipação das ações necessárias para o atendimento dos pedidos e a um ganho de agilidade da cadeia, com reflexo positivo de desempenho no elemento "tempo" do serviço ao cliente.

No elemento "confiança", verificou-se que o desempenho satisfatório da CCF nos indicadores ligados a este elemento está relacionado diretamente à integração do processo de atendimento de pedidos no que se refere à embalagem, expedição, transporte e entrega de produtos, entre fabricantes e clientes, porém depende também de fatores internos às organizações. No caso estudado constatou-se a importância da competência dos fabricantes nos processos internos de planejamento e controle de produção suportados, como já dissemos, por sistemas de gestão integrados tipo ERP, sem o que, o desempenho no elemento "confiança" não seria satisfatório. No entanto, a competência nessa atividade, por si só, não seria suficiente não fosse a definição clara das condições de expedição, transporte e entrega, refletidas pelos fatores de integração relacionados ao uso comum de equipamentos e operadores logísticos.

No elemento "comunicação", verifica-se que o desempenho no indicador ligado a este elemento está relacionado diretamente à integração do processo de atendimento de pedidos, no que se refere à manutenção e gestão da informação entre fabricantes e clientes. No caso da CCF, pode-se verificar que o alto grau de implementação de sistemas integrados de comunicação entre fabricantes e clientes, reflete positivamente na satisfação destes. Cabe lembrar que, no caso estudado, as deficiências ainda existentes na maioria dos fabricantes na manutenção de sistemas de comunicação direta com os clientes são supridas pela ação dos agentes intermediários locais. Por outro lado, podemos afirmar ainda que o desempenho satisfatório no elemento "comunicação" do serviço ao cliente está relacionado também à competência interna na gestão das informações sobre o pedido, o que no caso dos fabricantes de calçados de Franca é feito por meio dos sistemas ERP, como já mencionado.

Com relação ao elemento "conveniência", pode-se afirmar que o desempenho nos indicadores ligados a este elemento está diretamente relacionado à integração do processo de atendimento de pedidos entre fabricantes e clientes, no que se refere ao processamento e entrega, o que pode ser constatado pela flexibilidade no atendimento a requisitos especiais de embalagem e de mix de produtos, refletida nos respectivos fatores de integração. No entanto, levando em conta o significado abrangente deste elemento que envolve vários aspectos de flexibilidade no atendimento a requisitos especiais dos clientes, os fatos constatados permitem concluir que o desempenho satisfatório no elemento "conveniência" do serviço ao cliente está relacionado também à integração dos processos de atendimento de pedidos e desenvolvimento de produtos, entre a empresa focal da cadeia e seus fornecedores a montante. No caso estudado, ficou evidenciada a ação dos agentes intermediários locais na criação de condições de contorno para a falta de integração existente entre fabricantes e fornecedores neste processo, porém, no que diz respeito à flexibilidade nos prazos de entrega, essa falta de integração continua limitando o desempenho da cadeia.

Isso posto, pode-se concluir que, com relação à proposição de pesquisa colocada como foco deste trabalho, o desempenho da CCF no serviço ao cliente está associado à implementação dos fatores de integração dos processos de "atendimento de pedidos" e "gestão da demanda" entre fabricantes e clientes, porém a implementação desses fatores é condição necessária porém não suficiente para garantir o desempenho satisfatório. Esse desempenho está relacionado também à integração entre os fabricantes e seus fornecedores principais a montante e a competências internas nas organizações fabricantes de calçados.

A Tabela 6 procura resumir o quadro de relacionamento entre os fatores de integração de processos e os elementos do serviço ao cliente na CCF, de acordo com os dados obtidos na pesquisa de campo.

Tabela 6. Matriz de relacionamento. Fatores de integração $\times$ elementos do serviço ao cliente na CCF.

\begin{tabular}{|c|c|c|c|c|c|}
\hline & & \multicolumn{4}{|c|}{ Elementos do serviço ao cliente } \\
\hline & & Conveniência & Comunicação & Confiança & Tempo \\
\hline \multirow{4}{*}{ 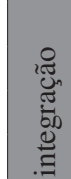 } & F1: definição da frequência de entregas & & & & \\
\hline & F2: customização de embalagens & & & & \\
\hline & F3: compartilhamento dos planos de produção & & & & \\
\hline & F4: uso comum de equipamentos logísticos & & & & \\
\hline \multirow{4}{*}{ 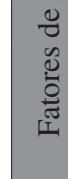 } & F5: conhecimento dos níveis dos estoques & \multicolumn{4}{|c|}{ Não aplicável } \\
\hline & F6: acesso ao sistema de planejamento & \multicolumn{4}{|c|}{ Não aplicável } \\
\hline & F7: uso comum de operadores logísticos & & & & \\
\hline & F8: utilização conjunta de EDI/Networks & & & & \\
\hline
\end{tabular}




\section{Conclusões}

Os novos parâmetros de competitividade na economia globalizada fizeram com que as empresas tivessem de desenvolver novas competências para manterem-se no mercado. Uma dessas competências é o estabelecimento de vínculos mais fortes e duradouros com seus clientes e fornecedores, de forma a estabelecer uma cadeia capaz de fazer frente a esses novos parâmetros e obter vantagens para todos os seus componentes.

Este trabalho procurou identificar em que medida o desempenho no serviço ao cliente está associado à integração dos processos de gestão da demanda e atendimento de pedidos entre os fabricantes de calçados e os clientes da CCF. Foi executada uma extensa revisão da bibliografia existente sobre a gestão da cadeia de suprimentos, a integração de processos e os parâmetros de avaliação do serviço ao cliente, com o objetivo de identificar o estado da arte com relação a estes assuntos e facilitar a proposição de uma matriz de relacionamento a ser testada.

As evidências obtidas na pesquisa de campo permitiram verificar que a CCF tem, na visão dos clientes, desempenho aceitável nos elementos "confiança", "comunicação" e "conveniência" do serviço ao cliente, porém em alguns aspectos esse bom desempenho é excessivamente dependente da ação dos agentes intermediários, como por exemplo, na manutenção de sistemas de comunicação direta com os clientes e no desenvolvimento de novos produtos. Por outro lado, no elemento "tempo" o desempenho verificado pode ser considerado sofrível, o que está relacionado à falta de integração entre os fabricantes de calçados e os fornecedores de couro.

Pode-se concluir que o desempenho da CCF no serviço ao cliente está associado diretamente à integração dos processos de atendimento de pedidos e gestão da demanda ao longo da cadeia, envolvendo não apenas a integração com clientes, porém dependendo também da integração com os fornecedores a montante da empresa focal da cadeia, no caso os fabricantes de calçados estabelecidos na cidade. Esse desempenho está relacionado também à existência de competências internas relacionadas aos processos mencionados, nas organizações estudadas e do desenvolvimento de outras hoje supridas pelos agentes intermediários. Estas conclusões nos permitem sugerir que o reposicionamento da CCF no mercado e a manutenção de sua competitividade no longo prazo, passam pela adoção de medidas de melhoria da integração dos processos entre fabricantes de calçados e fornecedores de couro no que diz respeito à melhoria da qualidade deste insumo, bem como na sua disponibilização nas quantidades necessárias para atendimento da demanda. A integração do processo de desenvolvimento de produtos entre fabricantes e fornecedores também é primordial para a melhoria do desempenho da cadeia, especificamente nos elementos "tempo" e "conveniência" do serviço ao cliente.

Com relação à integração da cadeia com seus clientes no mercado global, o trabalho aqui desenvolvido mostrou a necessidade de ações que permitam diminuir a dependência dos fabricantes de calçados dos agentes intermediários estabelecidos na região de Franca, por meio da melhoria da integração dos processos de gestão da demanda, manutenção e gestão de informações e processamento de pedidos, entre fabricantes e clientes. Assim, ações como o acompanhamento mais próximo do mercado para obtenção de informações sobre as tendências da moda, a criação de canais de comunicação direta com clientes e a criação de estruturas próprias para desenvolvimento de novos produtos pelos fabricantes são algumas medidas que podem levar à melhoria do desempenho da CCF no serviço ao cliente.

Apesar de não haver a possibilidade de generalização das conclusões obtidas, dada a abordagem utilizada, a complexidade das cadeias de suprimentos e suas especificidades nos vários setores econômicos, a metodologia desenvolvida e empregada na pesquisa de campo para levantamento e análise dos dados se mostrou consistente e eficaz, podendo servir de referência para novas pesquisas sobre o tema.

Com isso, acreditamos que este trabalho alcançou plenamente seus objetivos, contribuindo para o aprofundamento do conhecimento sobre o tema tratado e para a construção da teoria sobre a gestão e integração das cadeias de suprimento, além de disponibilizar uma ferramenta útil para que o presente estudo possa ser replicado em outras situações. 


\title{
Processes integration in supply chain and customer service performances: a study of a footwear industry in Franca, SP
}

\begin{abstract}
The globalization process and the digital revolution have brought new challenges for the companies' competitiveness. One of these new requirements is the change of the managerial scope of the entire supply chain. The management of a supply chain requires, among other aspects, integrating key-business processes along the chain. In this sense, this work has the main purpose of identifying the relationship between processes integration along the supply chain and its customer service performance. In order to achieve this aim, an exploratory research was conducted, focusing on a footwear supply chain located in the city of Franca, state of São Paulo, Brazil, which constitutes itself a good example of a consolidate supply chain already inserted in the international footwear market. The results obtained enable to conclude that the performance of the customer service in the studied footwear supply chain is directly related to the integration of order fulfilment processes, demand management, and product development processes involving not only the integration of shoe manufacturers with customers, but also with key suppliers. It still can be pointed out that this performance is also related to the existence of internal competences in the processes considered in the studied companies.
\end{abstract}

Keywords: Supply chain. Customer service. Process integration. Footwear industry.

\section{Referências bibliográficas}

ASSOCIAÇÃO BRASILEIRA DAS INDÚSTRIAS DE CALÇADOS ABICALÇADOS. Resenha estatística. Disponível em: <www. abicalçados.com.brwww.abicalçados.com.br>. Acesso em: Abril de 2009.

ARAGÃO, A. B. et al. Modelo de análise de cadeias de suprimentos: fundamentos e aplicação às cadeias de cilindros de GNV. Gestão e Produção, v. 11, n. 3, p. 299-311, 2004.

ARAVECHIA, C. H. M. Avaliação de desempenho de cadeias de suprimentos. 2001. 114 p. Dissertação (Mestrado em Engenharia de Produção) - Universidade Metodista de Piracicaba, Piracicaba.

BALLOU, R. H. Business logistics management: planning, organizing, and controlling the supply chain. Englewood Cliffs: Prentice Hall, 1999.

BOWERSOX, D.; CLOSS, D. J. Logística empresarial: o processo de integração da cadeia de suprimento. São Paulo: Atlas, 2001.

BREWER, P. C.; SPEH, T. W. Using the balanced scorecard to measure supply chain performance. Journal of Business Logistics, v. 21, n. 1, p. 75-93, 2000

COSTA, A. B. Estudo da competitividade de cadeias integradas no Brasil: impactos das zonas de livre comércio - cadeia: CouroCalçados. Campinas: UNICAMP-IE-NEIT, 2002.

COYLE, J. J.; BARDI, E. J.; LANGLEY Jr., J. The management of business logistics: a supply chain perspective. 7 ed. Toronto: Thomson Learning, 2003.

CROXTON, K. L.; GARCÍA-DASTUGUE, S. J.; LAMBERT, D. $M$. The supply chain management processes. The International Journal of Logistics Management, v. 12, n. 2, p. 13-36, 2001.

DAVENPORT, T. H. Reengenharia de processos. Rio de Janeiro: Campus, 1994.

ELLRAM, L. M. The implementation of target costing in the United States: theory versus practice. The Journal of Supply Chain Management, Winter, p. 13-25, 2006.

FIGUEIREDO, K. et al. Improving customer service in the distribution logistics of grocery products in Brazil: a longitudinal study. Rio de Janeiro: Centro de Estudos em Logística; COPPEAD;
UFRJ, 2002. Disponível em: <www.centrodelogistica.com.br> Acesso em: 01 de Junho de 2006.

FROHLICH, M. T.; WESTBROOK, R. Arcs of integration: an international study of supply chain strategies. Journal of Operations Management, n. 19, p. 185-200, 2001.

GIL, A. C. Como elaborar projetos de pesquisa. São Paulo: Atlas, 2002.

HAYES, R. et al. Operations, strategy, and technology: pursuing the competitive edge. Englewood Cliffs: John Wiley \& Sons, 2005.

HIJJAR, M. F.; GERVÁSIO, M. H.; FIGUEIREDO, K. F. Mensuração do desempenho logístico e o modelo World Class Logistics - Parte 1. Rio de Janeiro: Centro de Estudos em Logística; COPPEAD; UFRJ, 2005. Disponível em: <www.centrodelogistica.com.br>. Acesso em: 01 de Junho de 2006.

KUEI, C. H.; MADU, C. N.; LIN, C. The relationship between supply chain quality management practices and organizational performance. International Journal of Quality \& Reliabiliity Management, v. 18, n. 8, p. 864-872, 2001.

LAMBERT, D. M.; STOCK, J. R.; ELLRAM, L. M. Fundamentals of logistics management. New York: McGraw-Hill, 1998.

LAMBERT, D. M.; COOPER, M. C. Issues in supply chain management. Industrial Marketing Management, v. 29, n. 1, p. $65-83,2000$.

LAMBERT, D. M.; POHLEN, T. Supply chain metrics. The International Journal of Logistics Management, v. 12, n. 1, p. 1-18, 2001.

LAZZARINI, S. G. Estudos de caso: aplicabilidade e limitações do método para fins de pesquisa. Economia Empresa, v. 2, n. 4, p. 17-26, 1995.

LEE, C. W.; KWON, Y. W. G.; SEVERANCE, D. Relationship between supply chain performance and degree of linkage among supplier, internal integration, and customer. Supply Chain Management: An International Journal, v. 12, n. 6, p. 444-452, 2007.

SECRETARIA DE COMÉRCIO EXTERIOR DO MINISTÉRIO DO DESENVOLVIMENTO, INDÚSTRIA E COMÉRCIO 
EXTERIOR - SECEX/MDIC. Estatísticas. Disponível em: <www.mdic.gov.br/sitio/secex/www.mdic.gov.br>. Acesso em: Agosto de 2006.

Sindicato das Indústrias de Calçados de Franca - SINDIFRANCA. Resenha estatística. Disponível em: <www.sindifranca.org. brwww.sindifranca.org.br>. Acesso em: Agosto de 2006.

SUPPLY-CHAIN COUNCIL. SCOR: supply chain operations reference model - overview, version 9.0. Disponível em: <www. supply-chain.orgwww.supply-chain.org > Acesso em: Novembro de 2008.

STEPHENS, S. Supply chain council \& supply chain operations reference (scor) model overview. Disponível em: <www. supply-chain.org >. Acesso em: 21 de Setembro de 2001.
SU, J. C. P. Evaluation of supply chain strategies for mass customization. 2004. 79 p. Tese (Doutorado em Gestão de Operações) - School of Management, Georgia Institute of Technology, Atlanta.

TRKMAN, P. et al. Process approach to supply chain integration. Supply Chain Management: An International Journal, v. 12, n. 2, p. 116-128, 2007.

VICKERY, S. K. et al. The effects of an integrative supply chain strategy on customer service and financial performance: an analysis of direct versus indirect relationships. Journal of Operations Management, n. 21, p. 523-539, 2003.

YIN, R. K. Estudo de caso: planejamento e métodos. 2 ed. Porto Alegre: Bookman, 2001.

\section{Sobre os autores}

\section{Wilson de Castro Hilsdorf}

Departamento de Engenharia de Produção

Centro Universitário da FEI

Av. Humberto de Alencar Castelo Branco 3972, CEP 09850-901, São Bernardo do Campo, SP

email: wicastro@fei.edu.br

\section{Roberto Gilioli Rotondaro}

Departamento de Engenharia de Produção

Universidade de São Paulo, Escola Politécnica

Av. Professor Almeida Prado, travessa 2, n 128, CEP 05508-900, Cidade Universitária, São Paulo, SP

e-mail: rotondar@cwaynet.com.br

\section{Silvio Roberto Ignacio Pires}

Universidade Metodista de Piracicaba - UNIMEP

Rodovia do açúcar, km 156, CEP 13400-911, Piracicaba - SP

e-mail: sripires@unimep.br 